\title{
Fatigue analysis of rib-to-deck joints in steel orthotropic decks of Chongqi Bridge
}

\author{
Wang Hui ${ }^{\mathrm{a}}$, Han Suyu, He Shiqin and Yan Fei \\ College of Civil Engineering, North China University of Technology, China \\ awanghuitju@126.com
}

Keywords: Chongqi Bridge; Orthotropic steel deck plate; Rib-to-deck joints; fatigue

Abstract. Chongqi bridge is the longest-span continuous steel box girder bridge with an orthotropic steel deck in China. Due to the small thickness of both the deck plate and rib wall, the out-of-plane bending moments result in high local flexural stresses causing fatigue cracks to develop at the rib-to-deck joints. Aiming at the fatigue problem of this joint in the orthotropic steel bridge deck plate, the stress amplitude is calculated by FEM and the fatigue properties of rib-to-deck joints was analyzed according to the Eurocode specification under the condition of the single path loading. The results show that rib-to-deck joints have adequate fatigue strength and no fatigue cracks would occur at the location under the given fatigue loads.

\section{General situation of the Chongqi Bridge [1]}

The main bridge of Chongqi bridge is a 6-span single box single room variable cross-section continuous girder bridge of $102+4 \times 185+102(\mathrm{~m})$. The height of the girder is $4.8 \mathrm{~m}$ in the mid-span and $9 \mathrm{~m}$ in the intermediate support, while the depth-span ratio is $1 / 38.54$ and $1 / 20.55$, respectively. Fig.1(a) and (b) show the cross-section. Orthotropic deck is adopted in Chongqi bridge because of its favorable characteristics such as high load-carrying capacity, light weight, and short installation time.

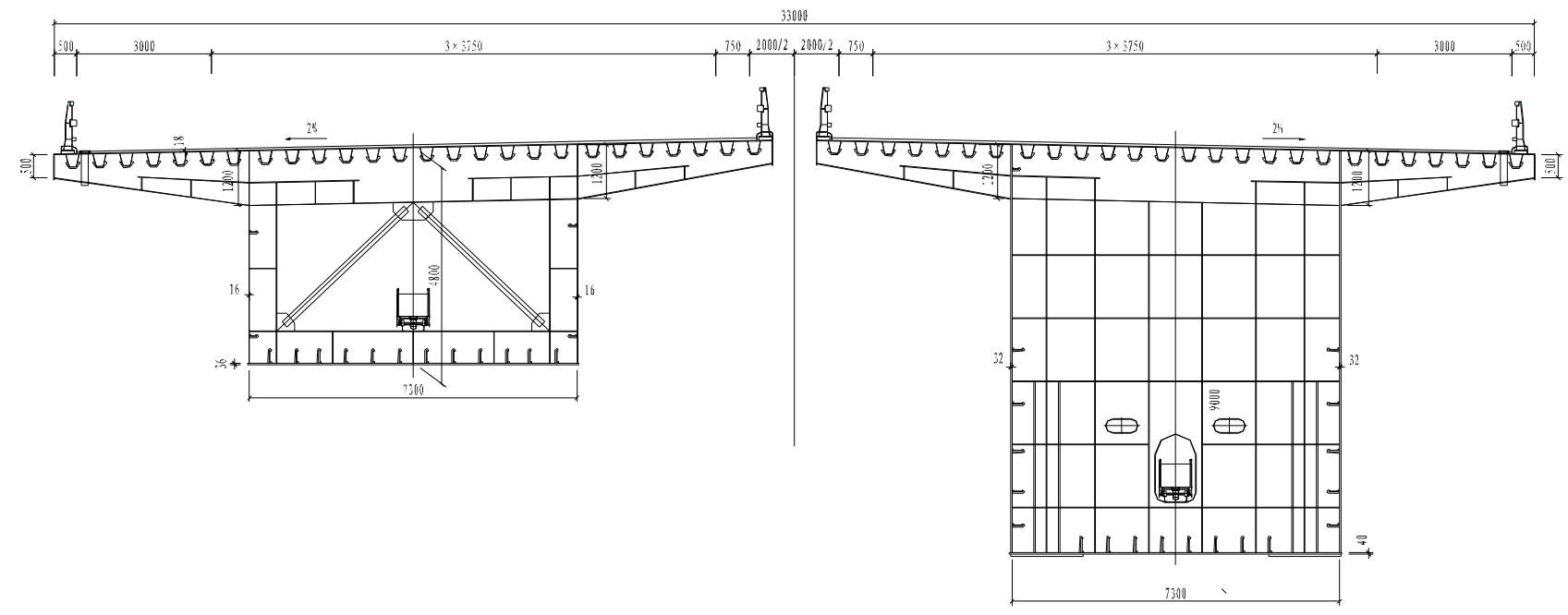

(a) Cross-section in the mid-span

(b) Cross-section in the intermediate support

Fig.1 Cross-section of steel box girder

The structural parameters of the Chongqi bridge main girder are briefly summarized as follows. The thickness of the deck plate is $18 \mathrm{~mm}$. The cross section of the longitudinal rib is $285 \mathrm{~mm}$ (top width) . $280 \mathrm{~mm}$ (height), and the thickness of the rib wall is $8 \mathrm{~mm}$. The spacing of the main girder web plates is $7.5 \mathrm{~m}$ and the thickness of the main girder web plates is $16 \mathrm{~mm}$. The spacing of the diaphragms is $5.6 \mathrm{~m}$, the spacing of transverse stiffener between the diaphragms is $2.8 \mathrm{~m}$. The thickness of the diaphragm plate is $12 \mathrm{~mm}$ and the height of the diaphragm is $1.2 \mathrm{~m}$. 


\section{The fatigue analysis of rib-to-deck joints in steel orthotropic decks}

Analysis method. This paper analyzes the fatigue properties of rib-to-deck joints in the orthotropic steel deck plate of Chongqi bridge based on the S-N curve method in accordance with miner rule [2]. The nominal stress history is obtained by one standard fatigue vehicle travelling along the lane. About the vehicles' transverse location, BS5400 supplies two methods: single path loading and multi path loading [3]. The single path loading is that the center line of all vehicles in any lane should be along a path parallel to and within $300 \mathrm{~mm}$ of the center line of the lane. The transverse position of the center line of the vehicle should be selected so as to cause the maximum stress range in the detail being considered. The Single path loading method is selected in this paper because it is simple and the corresponding calculation results are verified to be safe.

Fatigue of rib-to-deck joints. As the orthotropic steel deck undergoes many cycles of live load stress of high magnitude, fatigue cracks may develop at the weld connections between the deck plate and the rib. In the orthotropic decks stiffened with closed ribs, the rib-to-deck joint is more prone to fatigue failures than that in the orthotropic decks made with open ribs since the closed ribs constraint the transverse deformation of the deck plate while the open ribs do not. As shown in Fig.2, under the action of moving tire pressure, significant out-of-plane bending moments in the deck plate and rib wall at the rib-to-deck joint will be generated, and accordingly the fatigue cracks may develop due to the secondary stresses.
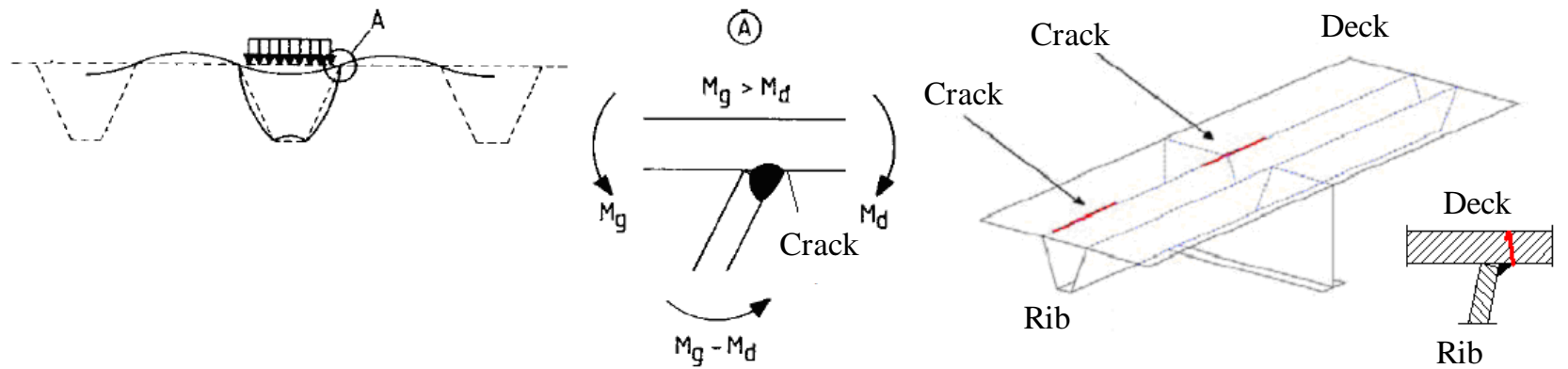

(a) Fatigue cracks from weld toe
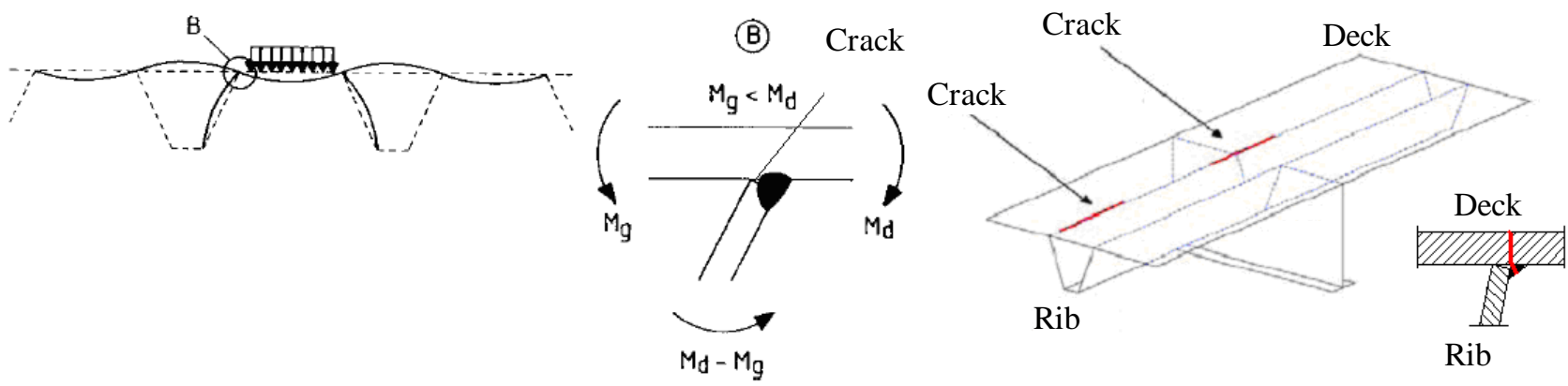

(b) Fatigue cracks from weld heel

Fig.2 Fatigue cracks of rib-to-deck joints

Fatigue vehicle model. Fatigue vehicle model should be obtained by a large quantity of statistical analysis. Comparing with accurate traffic statistical analysis in accordance with weigh-in-motion system in USA, Europe and Japan [4-6], less research has been done to predict fatigue durability with fatigue load in China. Considering the high frequency of heavily loaded trucks in China, fatigue vehicle Model 3 of Eurocode 2 Standard (single vehicle model) has been multiplied by 1.2 for safety, which 
means the $140 \mathrm{kN}$ axle weight vehicle model as shown in Fig. 3 is adopted as the fatigue vehicle model of Chongqi bridge.
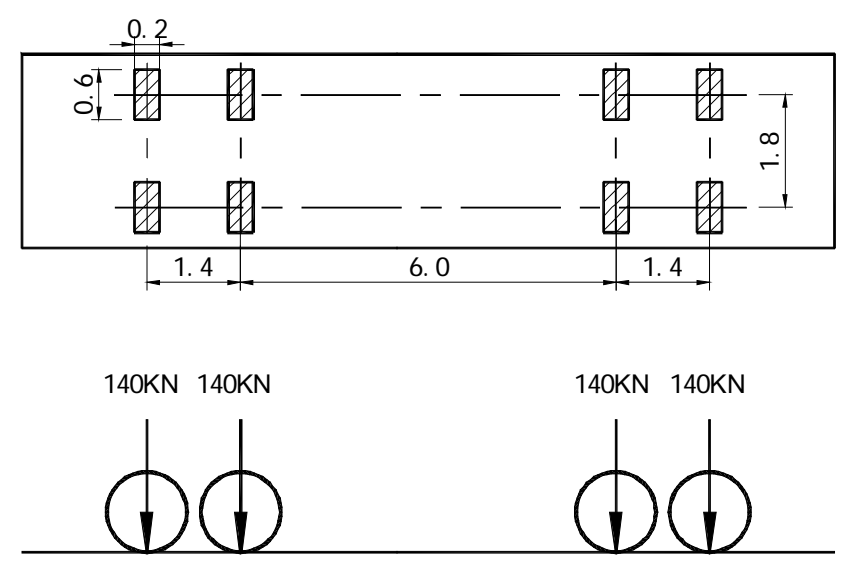

Fig.3 Fatigue vehicle model of Chongqi bridge

\section{Chongqi bridge's deck plate finite element analysis results}

The finite element model of local bridge deck plate is established with linear elastic shell elements to calculate the stress of critical fatigue details. The finite element model is intended to model the part of the deck in between the webs of box-girder [7]. It consists of 26 trapezoidal ribs supported by six transverse stiffeners. The longitudinal length of the model is 5 times the spacing of two adjacent transverse stiffeners, as shown in Fig.4. Line bracing is constrained to simulate the support of box girder webs. Based on single path loading method, the stress history of rib-to-deck joints is calculated under vehicle load as mentioned in Fig.3. The stress history of rib-to-deck joints is shown in Fig.5 and Table 1 shows the maximum stress amplitude of these details.

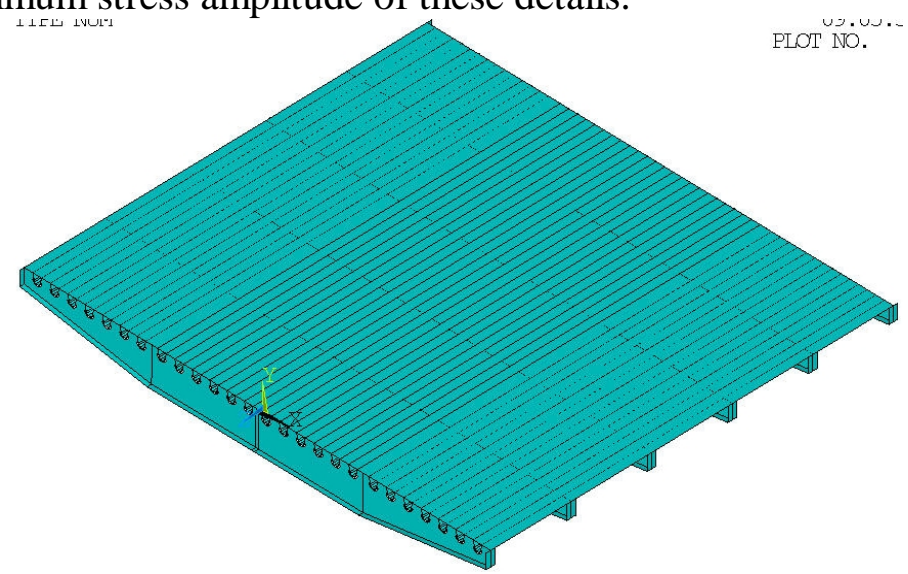

Fig.4 Finite element model of local bridge deck plate

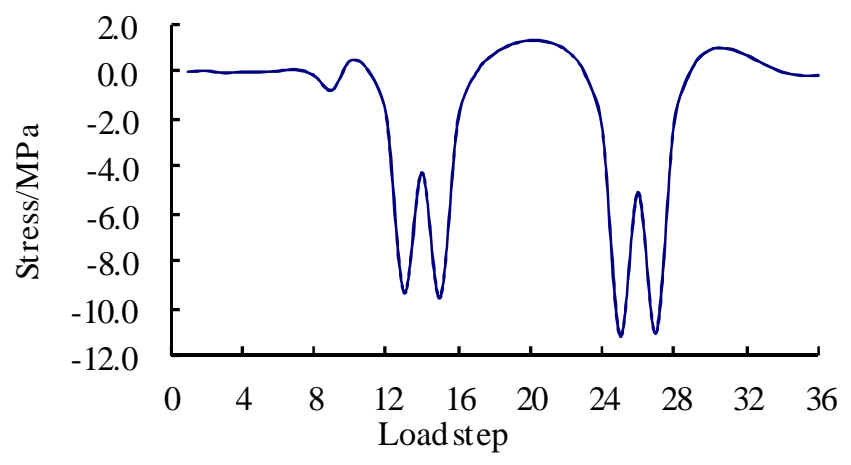

Fig.5 Stress history of rib-to-deck joints 
The design specifications of highway bridge fatigue in China adopts the stress ratio method, in this paper a comparison of the fatigue stress amplitude of rib-to-deck joints in chongqi bridge and stresses strengths in "EN1995-1-9:2005 Eurocode3: Design of steel structures part1-9: Fatigue" is made, as shown in table 1.

Table 1 Fatigue analysis results

\begin{tabular}{l|c|c|c|c}
\hline Location of fatigue analysis & Analysis of stress & $\begin{array}{c}\text { EC3 : fatigue } \\
\text { strength at 2 } \\
\text { million cycles } \\
\text { ( MPa })\end{array}$ & $\begin{array}{c}\text { EC3: } \\
\text { constant } \\
\text { amplitude } \\
\text { fatigue limit ( } \\
\text { MPa })\end{array}$ & $\begin{array}{c}\text { maximum } \\
\text { stress } \\
\text { amplitude } \\
\text { ( MPa ) }\end{array}$ \\
\hline $\begin{array}{l}\text { Fillet weld connection of } \\
\text { longitudinal rib to deck plate } \\
\text { (biggest positive bending } \\
\text { moment at longitudinal rib) }\end{array}$ & $\begin{array}{l}\text { Stress of top flange of } \\
\text { longitudinal rib }\end{array}$ & 100 & 74 & 10 \\
\hline
\end{tabular}

\section{Conclusions}

As shown in table 1, the calculated fatigue stress for the rib-to-deck joints of the orthotropic steel deck plate of Chongqi bridge under fatigue vehicle model turns out to be far less than the constant amplitude fatigue limit of corresponding detail categories at 5 million cycles based on $\mathrm{S}-\mathrm{N}$ curves. No more detailed damage analysis is needed according to Palmgren-Miner rule. In fact, considering the stiffness of bridge deck pavement, dispersion of the traffic load, the actual slower than the design vehicle speed, calculation error (the measured stress is less than the calculated stress) and other reasons, the actual stress amplitude is less than the data in table 1, for instance, the stress is reduced by the calculated correction factor 0.8 and the transverse distribution factor 0.85 in Japanese specification. So the rib-to-deck joints of Chongqi bridge deck plate have adequate fatigue strength.

\section{Acknowledgements}

This work was financially supported by Beijing Education Commission science \& technology planning project and the student science \& technology activities of North China University of Technology.

\section{References}

[1] Design document of Yangtze River bridge (Jiangsu province) between Chongming and Qidong, Beijing: CCCC Highway Consultants CO., Ltd., 2008

[2] Yongji Shi,Zhiqiang Shi. Welding handbook volume 3, chapter 18, Beijing: China Machine Press, 2001

[3] British Standards Institution. BS 5400, Part10: Code of practice for fatigue. London: British Standards Institution, 1980

[4] Japan Road Association (JRA). Fatigue design specifications for steel bridges, Japan Road Association, Tokyo; 2002.

[5] EN1993-1-9:2005 Eurocode 3: Design of Steel Structures Part 1-9: Fatigue. Brussels: European Committee for Standardization, 2005.

[6] EN1993-2:2006 Eurocode 3: Design of Steel Structures Part2: Steel bridges. Brussels: European Committee for Standardization 2006.

[7] Xiao Z G , Yamada K , Ya S , Zhao X L . Stress analyses and fatigue evaluation of rib-to-deck joints in steel orthotropic decks. International Journal of Fatigue, Vol. 30(2008) , p1387-1397 